\title{
Correction to: Kusatsu-Shirane volcano eruption on January 23, 2018, observed using JMA operational weather radars
}

\author{
Eiichi Sato * (1)
}

\section{Correction to: Earth Planets Space (2021) 73: 117 https://doi.org/10.1186/s40623-021-01445-w \\ After publication of this article (Sato 2021), it is noticed the article contained some errors:}

(1) The levels of headings are incorrect. The correct levels of headings are provided below.

First level headings:

Introduction

Kusatsu-Shirane volcano

Phreatic eruption on January 23, 2018

Methodology

Results

Discussion

Summary and conclusion
Second level headings:

Modified probabilistic estimation method Erupted mass estimation methods

(2) The author's affiliation should be updated to:

Meteorological Research Institute, 1-1 Nagamine, Tsukuba, Ibaraki 305-0052, Japan

The original article has been updated.

Published online: 21 June 2021

\author{
Reference \\ Sato E (2021) Kusatsu-Shirane volcano eruption on January 23, 2018, observed \\ using JMA operational weather radars. Earth Planets Space 73:117. \\ https://doi.org/10.1186/s40623-021-01445-w
}

\section{Publisher's Note}

Springer Nature remains neutral with regard to jurisdictional claims in published maps and institutional affiliations. 